\title{
Children's use of phonological encoding when reading for meaning
}

\author{
ESTELLE ANN DOCTOR and MAX COLTHEART \\ Birkbeck College, University of London, London WCIE 7HX, England
}

\begin{abstract}
The role of phonological recoding in children's reading was investigated by means of a task requiring comprehension of sentence meaning: The child's task was to decide whether a sequence of printed letter strings was a meaningful sentence or not. Meaningless sentences that are meaningful when phonologically recoded (e.g., "He ran threw the street") produced more incorrect responses than did meaningless sentences that remain meaningless when phonologically recoded (e.g., "He ran sew the street"). The difference in error rates between the two sentence types diminished as a function of age. Control experiments showed that these results were not due to visual similarity effects, nor to imperfect ability to spell homophones. It was concluded that very young readers rely extensively on phonological recoding when reading for meaning; as they grow older, reliance on visual encoding becomes progressively more important.
\end{abstract}

This paper is concerned with the strategies that young children use to encode words when reading continuous text for meaning. A variety of theoretical views can be taken about this, the extremes being represented, on the one hand, by the view that children treat words as visual wholes (and ignore the fact that words contain components, letters, which are common to many words and which permit, in principle, the conversion of a visual stimulus into a phonological representation) and, on the other hand, by the view that children profit from the fact that they can already understand speech when they are trying to learn to read and so make use of the alphabetic nature of English script by converting letter sequences into phonological representations, which are then comprehended.

This theoretical contrast, belonging to the psychology of reading, is paralleled by that between whole-word and phonic methods of teaching reading, a contrast that belongs to the pedagogy of reading. A distinction needs to be drawn between the two contrasts, however, since even if we knew precisely how children read for meaning, we would still not necessarily know how best to teach them. For example, if it were convincingly demonstrated that young readers did read by carrying out conversions from printed words to phonological representations, it would remain for us to discover whether they could best be taught this by explicitly teaching conversion procedures (as in phonics instruction) or by providing many examples of words and heir pronunciations (as in whole-word instructional methods) and relying on the children to learn implicitly how print is converted to sound. Our concern in this paper is with the psychological question rather than the pedagogical question.

The relative importance of visual vs. phonological

This research was supported by Social Science Research Council Grant HR/4017/1 to Max Coltheart. encoding for young readers has been investigated in a variety of ways. Perhaps the most frequent approach has been to contrast groups of good and poor readers. Such research has often been prompted by the reasoning that, if one can discover some basic cognitive task that good readers are good at and bad readers are bad at, then one can deduce that learning to read must rely at least in part on this cognitive task. It has often been pointed out, however, that this reasoning confuses correlation with causation. For example, if one shows that good readers are faster and more accurate at naming single letters than are bad readers (which is the case; Chall, 1967, reviews this work), one cannot therefore conclude that knowing letter names helps children to learn to read (and hence that learning to read must rely in part on using knowledge of letter names to convert a printed representation to a phonological representation). It is possible, even plausible, to argue that the direction of causality is opposite, that learning about letter names is a consequence of learning to read well, not a prerequisite, or that poor progress in reading discourages children and hence makes them perform more poorly in any task involving printed letters. Moreover, the possibility also exists that the relationship between reading ability and letter-naming ability is not causal at all and that the apparent correlation is due to the influence of some third variable (intelligence, socioeconomic class, ability to attend selectively; there are many possible candidates) that influences both how well a child learns to read and how well he learns to name letters.

This kind of objection can be raised against any investigation that seeks, by comparing good and bad readers, to discover something about the causation of reading deficiencies. Thus attempts to deduce something about how children read by comparing good and bad readers, which rely on such causal inferences, will scarcely be satisfactory. This objection applies even to such 
findings as those of Rozin, Bressmann, and Taft (1974), who showed that poor readers were so unaware of the relationships between letters and phonemes that they could not correctly pair up the spoken words "mow" and "motorcycle" with their printed equivalents. This inability is striking, but we do not know whether it is a cause or a consequence or poor reading. The same point can be made concerning demonstrations that good readers have superior knowledge of spelling-sound correspondences (e.g., Calfee, Venezky, \& Chapman, Note 1). Can we be sure that they are good at reading as a consequence of this superior knowledge, rather than having acquired this superior knowledge as a consequence of being good readers?

A second difficulty that arises in some basic research on the nature of reading in young children is the choice of a measure of reading ability, in particular, the choice between an oral test of reading and a silent test. Firth (1972) showed that good readers differed to an extraordinary degree from bad readers in the ability to convert letters to sounds. His measure of the latter ability was the number of pronounceable nonsense words a child could pronounce accurately. A group of 50 good readers averaged 128 out of 150 right; a group of 50 poor readers averaged 29 out of 150 . However, the tests used by Firth to measure reading ability were the Schonell RI and the Neale accuracy tests. Both are oral tests in which success on an item is credited when the item is pronounced correctly. It is not especially surprising that there is a strong correlation between how accurately a child can pronounce words and how accurately he can pronounce nonwords. If one takes the view that the essence of reading is understanding what a printed word means, rather than being able to pronounce it aloud, then it is not clear what Firth's finding tells us about how children encode words when they are reading. This would not be a difficulty if understanding what a word meant was always accompanied by being able to pronounce it and vice versa, but this is not always so. The two abilities must be at least partially separable, since damage to the left hemisphere can produce a disorder in which printed words are given completely incorrect pronunciations, yet at least some knowledge of their meanings remain (e.g., a patient reads "GNOME" as "pixie" and "THUNDER" as "storm"). This syndrome is known as "deep dyslexia" (Marshall \& Newcombe, 1973) or "phonemic dyslexia" (Shallice \& Warrington, 1975). The same point is made in another way by considering the findings of Thackray (1971), who showed that after 3 years of tuition in either i.t.a. or traditional orthography (t.o.), children who had been taught by i.t.a. were superior to t.o. children in accuracy of oral reading (Schonell and Neale accuracy) but not in comprehension (Neale comprehension). Thackray (1971, p. 215) commented thus: "The author, on a number of occasions, asked for the meaning of a word a child had given correctly, to find the child did not know what the word meant. It would seem then that in the author's sample there was some evidence to suggest that, in the i.t.a. reading, accuracy was outstripping understanding of the words read." Neale (1967) found that girls were superior to boys at oral reading, but not in reading comprehension. Viitaniemi (1965, cited in Downing \& Thackray, 1971, p. 19) found, with Finnish children, that boys were actually superior to girls in reading comprehension, but girls showed a small superiority over boys in oral reading. Sebesta (1964) found that oral reading was facilitated if children learned to read with an i.t.a.like artificial orthography, but there was no effect on reading comprehension. These various examples demonstrate the dissociability of the ability to pronounce a printed word aloud correctly from the ability to understand what a printed word means.

Provided that one is interested in reading as reading for meaning, then, research attempting to show the importance of phonological encoding for oral reading is unsatisfactory; it is essential to use a reading task that necessarily requires access to meaning while not necessarily requiring the conversion of print to sound.

This methodological problem is, if anything, more acute when one considers research on skilled reading. Here the experimental tasks most frequently used (for example, the lexical decision task, reading aloud, samedifferent judgment, tachistoscopic report, and so on) bear no obvious relationship to the task of reading continuous prose for meaning, and hence, they may not be capable of providing much enlightenment about how such reading is performed. In particular, these experimental tasks do not require the subject to gain access to the meanings of the words with which the experimenter confronts him. Such considerations led Baron (1973) to devise a task that would require his subjects, skilled readers, to gain access to the meaning of printed text. The task was to classify such phrases as "Tie the not," "He is know," or "He is ill" as meaningful or meaningless. To the extent to which access to the meanings of printed words is accomplished by a conversion of print to phonology, the subject will have difficulty in giving a correct "no" response to a phrase like "Tie the not," which becomes meaningful once it has been converted from a visual to a phonological representation.

The results of this experiment were unclear (phrases that sounded meaningful did not produce slower "no" responses than phrases that sounded meaningless, but they did produce more than twice as many errors, and this difference in error rates was significant), but the task seems a promising one with children from 6 to 10 years of age. Briefly, each child was given 16 short printed sentences, one at a time, and was asked to say whether each sentence made sense or not. Eight of the sentences were meaningful; eight were nonsensical. of the eight meaningless sentences, four became meaningful when converted to a phonological representation (e.g., "She blue up the balloon") and four remained meaning- 
less (e.g., "She know up the balloon"). Comparisons of responses to the former kinds of sentences with responses to the latter kinds will provide information about the use of letter-sound conversion when young children read continuous text for meaning.

\section{EXPERIMENT 1}

\section{Method}

Subjects. The subjects were 60 girls and 60 boys randomly selected from two London primary schools. They had been taught to read by eclectic ("mixed") methods. There were 12 boys and 12 girls of each of the following mean-age groups: 6.2 years, 7.3 years, 8.35 years, 9 years, and 10.5 years. None of the children had any reading problems, and all spoke English at home.

Materials. Twelve separate blocks of sentences were constructed. Each block consisted of 16 different sentences. Eight of the sentences in each block were meaningful and required a "yes" response; the remaining eight were meaningless and required a "no" response.

The eight meaningless sentences in a block were of four types, two sentences per type. (1) All word, sounds correct: An example is "I have know time." When phonologically recoded, this sounds meaningful. (2) All word, sounds wrong: An example is "I have blue time." This remains meaningless when phonologically recoded. (3) Nonword, sounds correct: An example is "I have noe time." This is like Type 1 above, except that it contains a nonword. (4) Nonword, sounds wrong: An example is "I have bloo time." This is like Type 2 above, except that it contains a nonword.

The eight meaningful sentences in a block consisted of two sentences containing homophones (e.g., "I have no time") and two nonhomophone sentences (e.g., "I have the time"). The remaining four meaningful sentences were merely fillers, to equate the number of "yes" and "no" responses, and they will not be discussed further.

Although each block included two of each of the six different sentence types, no two sentences in a block were phonologically identical. For example, if one of the sentences in the block was "I know him," the sentence for that block that was all word and sounded correct could not be "I no him," nor could the sentence in which the nonword sounded correct be "I noe him." Thus the 16 sentences seen by any one subject were all phonologically distinct from each other. The 144 sentences, which were formed into 12 blocks of six types, with two exemplars per type, are listed in Appendix A, Table I. Prior to the experiment, the sentences had been given to a pilot group of children aged between 5 and 8 years, and the final blocks of sentences were such that all the words used in them were known by all of these children.

Procedure. Testing took place over 10 days. Sessions were held in a quiet room in the school. Each child was tested individually in sessions lasting approximately $10 \mathrm{~min}$ each.
The child was seated behind a table, facing the experimenter. He was shown a practice sentence, with the initial letter and proper names, if any, written in large uppercase letters, and the remainder written in lowercase letters. Half of the boys and half of the girls at each age level were requested to read the sentence aloud and the remainder were asked to read it silently before answering "yes" if the sentence made sense and "no" if it did not. A distinction was drawn between the truthfulness of the sentence (e.g., a boy having to read the sentence "I have a green dress") and its meaningfulness. Other practice sentences were given until the child had been shown a couple of examples of each sentence type and his errors had been corrected and explained.

Subjects were randomly assigned to the 12 blocks of sentences, with two children of each age group receiving the same sentence, and their responses were recorded. A week before this experiment took place, every child had been shown each homophone and nonword that was to appear in his block of sentences. He was asked to pronounce the word and to make a sentence with it to ascertain whether he knew its meaning in isolation. The results of these pretests are discussed later.

\section{Results}

The means for the percentage of correct responses to all six sentence types are given in Table 1 .

Meaningful sentences containing no homophones vs. meaningful sentences containing homophones. A 5 (age levels) by 2 (sex) by 2 (sentence type) by 2 (reading aloud vs. reading silently) analysis of variance was carried out on these data. There was no significant effect of sentence type, which indicates that children do not find homophones more difficult to comprehend than nonhomophones. ${ }^{2}$ The only significant effect in this analysis was that reading aloud produced superior performance to reading silently $[F(1,100)=4.29$, $p<.05]$. Since this effect was not significant with the other four sentence types, we will not consider it further. No other effects were significant, although there was a consistent trend for sentences containing homophones to be more difficult. This effect may well be genuine and concealed in these data by a ceiling effect. Arcsin transformations were applied to the scores, and the analysis of variance results were similar to the above.

Effects of homophony on all-word meaningless sentences. Analysis of variance was used with the data from meaningless sentences containing only words to determine whether incorrect "yes" responses are more likely to occur when such sentences are phonologically meaningful. The relevant means are in Rows 3 and 4 of

Table 1

Percentage Correct Responses to Each of the Six Sentence Types and Percentage of Substitutions

\begin{tabular}{|c|c|c|c|c|c|c|}
\hline \multirow[b]{2}{*}{ Sentence Type } & \multirow{2}{*}{$\begin{array}{l}\text { Correct } \\
\text { Response }\end{array}$} & \multicolumn{5}{|c|}{ Age In Years } \\
\hline & & 6 & 7 & 8 & 9 & 10 \\
\hline Meaningful sentences containing no homophones & Yes & 89.6 & 97.9 & 95.8 & 95.8 & 95.8 \\
\hline Meaningful sentences containing homophones & Yes & 85.4 & 93.8 & 87.5 & 95.8 & 89.6 \\
\hline Meaningless all-word sentences that sound correct & No & 29.2 & 56.3 & 68.8 & 81.3 & 79.2 \\
\hline Meaningless all-word sentences that sound wrong & No & 91.7 & 95.8 & 95.8 & 97.9 & 97.9 \\
\hline Meaningless sentences containing nonwords that sound correct & No & 43.7 & 72.9 & 75.0 & 95.8 & 95.8 \\
\hline Meaningless sentences containing nonwords that sound wrong & No & 89.6 & 93.8 & 95.8 & 97.9 & 100.0 \\
\hline
\end{tabular}


Table 1. Performance was significantly worse with sentences that become meaningful when translated from a visual to a phonological code than with sentences that remain meaningless even in their phonological form $[F(1,100)=108.73, p<.001]$. Hence, children are more likely to say that a meaningless sentence makes sense if its phonological form is meaningful; in other words, they make considerable use of letter-to-sound translation in reading printed sentences for meaning.

Performance also improved significantly with age $[F(4,100)=8.71, p<.001]$, and there was a significant interaction between sentence type and age $[F(4,100)=7.12, p<.001]$ : The size of the performance difference between the two types of sentences decreased with age. This interaction may be a spurious consequence of a ceiling effect, since even with the youngest children, performance was above $90 \%$ with the phonologically meaningless sentences. Nevertheless, with phonologically meaningful sentences, performance increased steeply with increasing age, indicating that the older a child is, the less use he or she makes of a phonological reading strategy. No other effects were significant.

The same main effects and interactions were significant when an arcsin transformation was applied to the data.

Effects of homophony on meaningless sentences containing a nonword. The relevant means here are in Rows 5 and 6 of Table 1. Once again, performance was significantly worse with sentences whose phonological form is meaningful than with those whose phonological form is meaningless $[F(1,100)=42.09, p<.001]$, again indicating considerable use of phonological encoding in these readers. The reliance on such encoding decreases as age increases, since performance improves significantly with age $[F(4,100)=14.45, p<.001]$. Once again, there was an Age by Sentence Type interaction $[F(4,100)=8.12, p<.001]$, but this, too, may be due to a ceiling effect, in view of the uniformly high level of performance on phonologically meaningless sentences.

The age of the subject interacted significantly both with sex $[F(4,100)=2.70, p<.05]$ and with reading aloud vs. reading silently $[F(4,100)=2.60, p<.05]$. This was due to rather poor performance by 6 -year-old girls and by 6-year-old oral readers, but since this effect was not evident at other age levels, we will not discuss it further.

No other effects were significant.

Once again, reanalysis of the data after arcsin transformation yielded the same pattern of results.

Effects of the presence of a nonword. A comparison of the means in Row 3 of Table 1 with the means in Row 5 provides information about effects of nonwords. Both types of sentence here are meaningless but sound meaningful. The difference is that the sentences represented by Row 3 consist entirely of words, whereas those represented by Row 5 contain a nonword. Thus it would in principle be possible to respond "no" to the latter type of sentence simply by detecting the presence of a nonword. Performance was in fact significantly better with sentences that contained nonwords than with all-word sentences $[F(1,100)=16.65, p<.001]$. No other effects were significant. Performance also improved with age $[F(4,100)=16.13, p<.001]$.

\section{Discussion}

The many errors the children made in dealing with meaningless sentences that were phonologically meaningful suggests that phonological coding was taking place to a great extent while they were reading for meaning. Reading was not entirely phonologically mediated, however, even for 6-year-olds, since they did not invariably respond "yes" to nonsense sentences that were phonologically acceptable and since performance was improved when nonwords were present, even though these nonwords were homophonic with real words and thus could only have been detected as nonwords by using a visual code. The difficulties engendered by meaningless sentences that sounded correct diminished as the age of the reader increased. We suggest, then, that in the evaluation of the meaning of these printed sen tences, the younger children relied more on a phonological code, while children of 9 years and older relied largely on a visual code.

There were no significant differences between the sexes in this comprehension task, although sex differences have been found in reading. Thompson's (1975) review of the literature shows that girls are often superior to boys until the age of 10 years and that more boys than girls are found in remedial reading classes. Other studies have found differences in favor of girls in oral reading (Viitaneimi, 1965, cited in Downing \& Thackray, 1971, p. 19) and in reading rate, but not in accuracy or comprehension (Neale, 1967). Sex differences may occur in oral reading tasks that differ from the comprehension test used in this study. Some sex differences appear to be cultural, with American studies showing more frequent sex differences in favor of girls. Overall, the evidence is not conclusive.

Coltheart (1978) and Forster and Chambers (1973) and others have noted that a word's phonological code can be derived from its printed form in at least two ways: a nonlexical method (applying letter-sound rules) and a lexical method (accessing a word's entry in the internal lexicon and retrieving from this entry the word's phonological representation). Although often neglected, this is an important distinction, and it applies to the results of this experiment. The phonological code that causes children to have difficulty in rejecting meaningless sentences containing homophones that are phonologically appropriate could be obtained prelexically (by applying letter-to-sound rules to the printed form and using the resulting phonological code for purposes of lexical access) or postlexically (by accessing the 
lexical entry corresponding to the individual printed word, retrieving the word's phonological representation from this entry, and using the resulting phonological code during the attempt to comprehend the sentence as a whole). Either of these two possibilities would lead to the difficulties with meaningless sentences containing phonologically appropriate homophones that the children, especially the younger children, encountered. It is possible that even if the children did not use the nonlexical method, they may have been forced into using the lexical method because of the confusion caused by the visually incorrect word being phonologically appropriate to the syntactic and semantic context of the sentence. The older children may have been less tempted to yield to the wrong information provided by this code because they had more reading experience and were more familiar with the written forms of the words. Only the prelexical method, of course, is available for nonwords, so that the difficulties experienced with the meaningless sentences that contained a nonword that sounded correct in the context must represent a prelexical encoding effect.

There are several possible objections to the interpretation of this experiment. One may be to the design of the study, another may be inherent in the subjects, and a third in the materials.

First, it could be argued that the critical stimuli, the homophones, were unknown to the children and that they could not distinguish between the members of the homophone pairs. Next, it could be argued that the children were poor spellers and that this accounts for their inability to make semantic judgments based on visual features. Finally, it may have been the case that an incorrect word in the meaningless sentences that contained phonologically appropriate homophones and nonwords also looked more similar to the correct word than was the case with meaningless sentences that were both phonologically and visually wrong. For example, in the sentence "I will sea him today," the word "sea" looks like the correct word "see," whereas in the corresponding sentence "I will for him today," no such visual similarity exists. Perhaps children have difficulty with the former type of sentence because of this visual similarity effect, rather than because these sentences make sense phonologically.

Each of these objections will be dealt with in turn. The next experiment was an attempt to observe how the children pronounced and used the homophones and nonwords that were included in the sentences used in the above study when these items were presented in isolation and not in the context of a sentence.

\section{EXPERIMENT 2}

This experiment has to do with the objection that a child says "yes" to the printed sentence "The wind blue" because he believes the past tense of "to blow" is spelled "blue." If this were so, the effects observed in Experiment 1 would not represent evidence of phonological recoding; they would instead demonstrate imperfect knowledge of spelling. We therefore investigated how well a child could understand the homophonic words used in Experiment 1 and the extent to which he confused a single printed homophone with the other member of the homophonic pair. We refer to such a confusion as a "substitution." We also investigated the pronunciation of each word, to ensure that the homophonic words actually were homophonic in the child's speech.

\section{Method} study.

Subjects. The same subjects participated as in the previous

Materials. Each child was tested on a set of eight different words, six of which were the homophones and four the nonwords used in Experiment 1. Each stimulus was written with a thick black felt-tipped pen on a $6 \times 4$ in. record card. Each child saw the individual words, nonwords, and homophones that were presented to him in the context of a sentence in Experiment 1.

Procedure. Testing took place over 2 weeks, and sessions were held in a quiet room in the school. Each child was tested individually. Sessions lasted approximately $30 \mathrm{~min}$ for the younger children and $10 \mathrm{~min}$ for the older children.

The child was seated at a table, facing the experimenter. The cards were presented in random order, and after the first card of the deck had been shown, the child was asked to pronounce the word written on the card and then to explain its meaning either by using it in a sentence or as best he could By way of warning the child that there were nonwords present in the deck, the experimenter explained that he might never have seen some of the words before, but that he should deal with them as best he could.

\section{Results and Discussion}

Table 2 summarizes the data and gives the total percentages, averaged over all the words, for correct responses and errors, substitutions (i.e., using a homophone as its mate), and the percentage these substitutions were of the total errors in usage. This table reveals that there were relatively few pronunciation errors and that pronunciation improved with age. All the children made more usage errors than pronunciation errors, but these also decreased with age.

Although substitutions of one homophone for another, its mate, did occur, especially with the 6- and 7-year-old children, they were much too infrequent to explain the effects obtained in Experiment 1; a comparison between Table 1 and Table 2 indicates this. To take the worst case, 6 -year-old children confused $24 \%$ of the homophones by using their mates when the homophone was presented as a single printed word. In Experiment 1 this would reduce percent correct on meaningless but phonologically meaningful sentences to $76 \%$; but in Experiment 1 we observed performance far lower than this (29.2\%). Applying this argument consistently across Table 1 shows that substitutions cannot explain the effects evident there. This conclusion is confirmed, using a different technique, by the results of Experiment 3 . 
Table 2

Pronunciation (P) and Usage (U) of Homophones

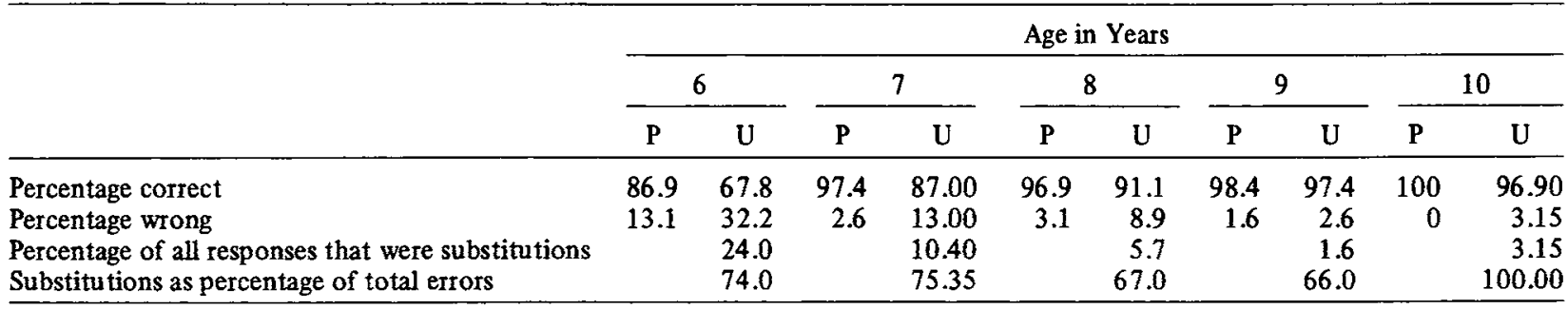

Inspection of the responses to individual homophones revealed that more errors were made on one member of some pairs than on others. For example, "blew," "four," "knew," "know," "won," "sew," "their," and "wear" tended to result in more substitution errors than did their homophonic mates. In order to ascertain whether children were substituting more within pairs that were highly similar in graphic similarity than within pairs that were less similar, the graphic similarities of the words were calculated and correlated with the children's errors in substituting one homophone for its pair. Weber's (1970b) formula for calculating graphic similarity was used. She has described it as follows: "The features taken into account are the number of letters shared by the stimulus-response pair, the position of shared letters within the words, the position of shared letters relative to each other, the average length of the words, and the difference in lengths between the stim. ulus and response words."

The formula is: $\mathrm{GS}=10[(50 \mathrm{~F}+30 \mathrm{~V}+10 \mathrm{C}) / \mathrm{A}+$ $5 \mathrm{~T}+27 \mathrm{~B}+18 \mathrm{E}]$, where $\mathrm{F}=$ the number of pairs of adjacent letters in the same order shared by $S$ and $R$; $\mathrm{V}=$ the number of pairs of adjacent letters in reverse order shared by $\mathrm{S}$ and $\mathrm{R} ; \mathrm{C}=$ the number of single letters shared by $S$ and $R ; A=$ average number of letters in $S$ and $R ; T=$ ratio of numbers of letters in the shorter word to the number in the longer; $B=1$ if the first letter in the response is the same as the first letter in the stimulus, otherwise $B=0$; and $E=1$ if the last letter in the response is the same as the last letter in the stimulus, otherwise $E=0$. The percentage of incorrect substitutions and the graphic similarity index for each pair of homophones is presented in Appendix B, Table I, Columns 3 and 4 , respectively. The correlation was not significant $(\mathrm{r}=.22)$, indicating that homophone pairs with high graphic similarity were not more likely to produce the wrong homophone in response to its mate than were low similarity pairs.

A further possibility was that if the homophones differed in frequency the child might use the more frequent member of the homophone pair more often and so incur errors when the less frequent member of the pair was presented. Word frequency tables such as that of Kucera and Francis (1970) had not been consulted when the homophone pairs were selected because their tables are derived from an adult population, and no comparable tables exist that have been standardized on British school children. However, the correlation between word frequency based on the Kucera and Francis ratings and the percentage of incorrect substitutions was calculated (see Appendix B, Table I, Columns 5 and 3, respectively) and was found to be negligible $(\mathrm{r}=-.04)$, indicating that usage of the more frequent members of the pair was not related to errors.

Nonwords. The nonword data were inspected in a manner similar to the above homophone data, but there was no significant correlation between graphic similarity of a nonword to a homophone and usage of the nonword as that homophone (see Appendix B, Table II, Columns 4 and 3, respectively) or between frequency of the graphically similar homophone and usage of the nonword as that homophone (Columns 5 and 3, respectively).

Many of the children, and particularly the older ones, recognized that the nonwords were not real words. This is indicated in Table 3 by the increase of "no" responses to nonwords and by the children's comments about not having encountered those words in print before. They could not have been quite sure that the nonwords were not simply unfamiliar real words, as the tendency to use "soe" as the less familiar "sow" (less familiar in comparison with "so" and "sew") reveals. However, the older subjects refused to use more than half the nonwords. Those nonwords that were used were usually given in the sense of similar-sounding homophones rather than as some other word.

The main purpose of this experiment was to show that the children knew how to pronounce and use homophones and to investigate how they would deal with nonwords when these items were presented to them in isolation.

A comparison of children's substitution of one homophone by its mate in usage and their responses to sentences in which a meaningless but phonologically appropriate homophone was incorporated in a sentence is shown in Table 4. Children of all ages made more errors in reading sentences than in the pronunciation or usage of isolated words, and there was no correlation between performance on these two tasks $(r=-.09)$ (see Appendix C, Table I).

Comparisons of children's usage of nonwords with their responses to sentences containing nonwords that 
Table 3

Pronunciation (P) and Usage (U) of Nonwords

\begin{tabular}{|c|c|c|c|c|c|c|c|c|c|c|}
\hline & \multicolumn{10}{|c|}{ Age in Years } \\
\hline & \multicolumn{2}{|c|}{6} & \multicolumn{2}{|c|}{7} & \multicolumn{2}{|c|}{8} & \multicolumn{2}{|c|}{9} & \multicolumn{2}{|c|}{10} \\
\hline & $P$ & $\mathrm{U}$ & $\mathbf{P}$ & $\mathrm{U}$ & $P$ & $\mathrm{U}$ & $\mathbf{P}$ & $\mathrm{U}$ & $P$ & $\mathbf{U}$ \\
\hline As a similar-sounding real homophone & 68.8 & 63.5 & 69.8 & 40.7 & 44.8 & 36.5 & 55.2 & 23.95 & 51.1 & 15.6 \\
\hline As some other real word & 15.6 & 15.6 & 6.2 & 4.1 & 12.5 & 7.2 & 2.1 & 7.30 & 1.1 & 2.1 \\
\hline No response & 15.6 & 20.9 & 24.0 & 55.2 & 42.7 & 56.3 & 42.7 & 68.75 & 48.0 & 82.3 \\
\hline Percentage used as a similar-sounding real word* & & 80.2 & & 90.8 & & 83.5 & & 76.64 & & 88.0 \\
\hline
\end{tabular}

*Percentage used as a similar-sounding real word of total nonwords used as real words.

Table 4

Comparison Among the Percentage of Incorrect Substitutions in Usage, Incorrect Acceptances, and lncorrect Substitution in Spelling

\begin{tabular}{|c|c|c|c|c|c|}
\hline & \multicolumn{5}{|c|}{ Age in Years } \\
\hline & 6 & 7 & 8 & 9 & 10 \\
\hline Percentage of substitution of one homophone by its mate in usage** & 24.0 & 10.4 & 5.7 & 1.60 & 3.15 \\
\hline Percentage of incorrect acceptances of meaningless all-word sentences that sound correct* & 70.8 & 43.7 & 31.2 & 18.70 & 20.80 \\
\hline Percentage of nonwords used as phonologically similar real words** & 63.5 & 40.7 & 36.5 & 23.95 & 15.60 \\
\hline Percentage of incorrect acceptances of meaningless nonword sentences that sound correct* & 56.3 & 27.1 & 25.0 & 4.20 & 4.20 \\
\hline Percentage of substitution in spelling $\dagger$ & 17.0 & 9.0 & 6.0 & 3.00 & 1.50 \\
\hline
\end{tabular}

*Experiment 1. **Experiment $2 . \quad$ tExperiment 3.

Table 5

Spelling Responses

\begin{tabular}{lrrrrr} 
& \multicolumn{4}{c}{ Age in Years } \\
\cline { 2 - 5 } & \multicolumn{1}{c}{6} & 7 & \multicolumn{1}{c}{8} & 9 \\
\hline Percentage correct & 31 & 42 & 86 & 90 & 94.5 \\
Percentage substitution of one homophone by its mate & 17 & 9 & 6 & 3 & 1.5 \\
Substitutions as percentage of errors & 25 & 28 & 40 & 29 & 27.0 \\
\hline
\end{tabular}

were phonologically meaningful in the context of the sentence is also shown in Table 5 . Fewer nonwords were incorrectly accepted in sentences than were incorrectly used as real words, and there was no correlation between performance on these two tasks $(\mathrm{r}=.27)$ (see Appendix C, Table II).

If the meaning of a word is accessed visually, then it should be relatively easy to access the meaning of homophones, because their similar sounds should not interfere with the meanings associated with them. Relatively few homophones were used as their mates by the children, indicating that they might well have been using a visual route to the lexicon for this task. This might lead one to expect that children should not accept the wrong form of a homophone when it appears in the context of a sentence in which it is phonologically, but not visually, appropriate. However, the results of the pronunciation and usage of nonwords experiment confound this result. If lexical access is purely visual, none of the nonwords should have been used as they were, and, more particularly, none of them should have been used as a similar-sounding homophone, yet many were. These results may mean that the child first tries to gain access to the lexicon visually. If the entry is not found, he may then try gaining access by encoding the item phonologically. This would allow him to make correct responses to homophones and to use nonwords as real words, and the effect might be increased when other semantic and syntactic cues are present, as in sentences. If the task demands differ in pronunciation and usage of isolated words compared with reading for meaning, the results might also differ. Neither words nor nonwords need to be recoded phonologically during reading for meaning. Without this demand on them, subjects might be encouraged to rely more on the visual features of the stimuli, which would enable them to reject nonwords more easily. This could apply to homophones as well, but the wrong homophones used in a phonologically suitable context might be more difficult to reject than a corresponding nonword: Children may reject unfamiliar words and nonwords because they do not recognize them as being genuine words. This strategy would help children of all ages to reject nonwords but would hinder younger children, who tend to make more substitution errors in rejecting phonologically appropriate but visually inappropriate homophones 
when both are equally familiar to them, especially if recoding to a phonological code takes place after the occurrence of access to individual word entries in the internal lexicon, but before semantic judgment of the sentence as a whole is made. Once again, this would not affect nonwords that are not represented visually in the lexicon unless they are phonologically encoded prior to lexical access, as they are in a pronunciation task, but as they need not be in a task involving semantic judgment.

\section{EXPERIMENT 3}

The aim of this study was to demonstrate that children were sufficiently proficient at spelling the homophones used in Experiment 1 to rule out any explanation of the results of that experiment in terms of inability to distinguish the spellings of homophones.

\section{Method}

Subjects. Where possible, the same children were used who had participated in the previous experiment. However, the spelling test was administered 1 year later, so that a new sample of 6-year-olds was selected. In addition, some children had left school, and it was not possible to obtain equal numbers of girls and boys in each age group. Twelve 6-year-old girls and 11 6-year-old boys, 10 7-year-old girls and 127 -year-old boys, 128 -year-old girls and 8 8-year-old boys, 129 -year-old girls and 129 -year-old boys, and 12 10-year-old girls and 610 -year-old boys served as subjects.

Materials. The 12 homophone pairs used in the previous experiments were the stimuli that had to be spelled.

Procedure. The children in a particular age group were seated at desks in their classrooms. A sheet of paper was distributed to each child. They were requested to furnish biographical data and were told that they were to be given a spelling test. The class teacher dictated 12 homophones, one at a time, pausing between each word for the children to write their answers. After this, each of the homophones was dictated in the context of a meaningful sentence, and the children were again asked to write down each homophone.

\section{Results and Discussion}

Table 5 gives the percentage of correct responses averaged over all the homophones, as well as the percentage of substitutions averaged over all the homophones and the percentage of errors that substitutions formed. The main reason for carrying out an analysis of spelling errors on the homophones was for purposes of comparison with the children's responses to homophones embedded in the context of meaningful sentences. It could be argued that the high rate of errors on meaningless sentences that nevertheless sounded correct when encoded phonologically (e.g., "He went to by the ball") occurred simply because the children did not know how to spell such homophones as BY and BUY. The results of this spelling study refute such an argument. Children who were presented aurally with the homophones in context and asked to spell them rarely produced the wrong member of the homophone pair, whereas they commonly accepted the wrong member when it was presented in print. A comparison of errors is presented in Table 4, where it is clear, for example, that an incorrect "yes" to the printed sentence "He went to by the ball" is far more common than is spelling "buy" as "by" in response to the spoken sentence "He went to buy the ball." Thus the results of Experiment 1 cannot be explained in terms of poor ability to spell homophones.

\section{EXPERIMENT 4}

It might be argued that the homophones and nonwords in the meaningless sentences that sounded correct when translated into a phonological code looked more similar to the correct word that should have been there than the corresponding words in the meaningless sentences, in which the homophones and nonwords neither looked nor sounded correct. On this argument, the effects observed in Experiment 1 are visual, not phonological. If the argument is correct, then the degree to which a child tends to respond with an incorrect "yes" to meaningless but phonologically correct sentences should depend on the degree of similarity between the incorrect word or nonword in the sentence and the word that should be there. Therefore, for each of these sentences, the graphic similarity index of Weber (1970a, $1970 \mathrm{~b}$ ) was used to measure graphic similarity of the incorrect word in the sentence to the word that should have been there. The results are shown in Appendix B, Table I for words and Appendix B, Table II for nonwords. Then the correlation between the proportion of error responses and the degree of graphic similarity was calculated across sentences. This correlation was not significant for the meaningless sentences that contained homophones that sounded correct $(r=.01)$ (Columns 6 and 3, respectively, both tables), indicating that those with high graphic similarity were no more likely to produce an incorrect "no" response than those with low graphic similarity. Thus the difficulty with these sentences is a phonological effect, not a visual effect.

The correlation, however, was significant for the meaningless sentences containing phonologically appropriate nonwords $(\mathrm{r}=-.46, \mathrm{p}<.02)$. It is thus possible that the difficulty here is a visual one and is not due to phonological encoding. In order to clarify this, a final experiment was carried out.

The point of this experiment was to compare performance on nonword sentences that were meaningless but sounded meaningful with performance on nonword sentences that neither looked nor sounded meaningful, when the two types of sentence were matched on graphic similarity. For example, the nonwords "bie" and "bak" have equal graphic similarity to the word "by," according to Weber's (1970a, 1970b) formula. Therefore, if children make more incorrect responses to "He went bie the town" than to "He went bak the 
town," this cannot be due to differential graphic similarity of the nonwords to the correct word "by"; it must be a phonological effect.

\section{Method}

Subjects. All the boys and girls in the second, third, and fourth grades of one of the London primary schools used in the previous experiment were tested. There were 15 girls and 12 boys whose average age was 6 years, 12 girls and 22 boys whose average age was 7 years, and 17 girls and 9 boys whose average age was 8 years. No older children were included in the sample because the previous experiments had shown that they made few errors.

Materials. In addition to some of the nonwords used in the previous experiments, several new nonwords were created, each of which had the same graphic similarity score as a particular nonword in the previous experiment, according to Weber's $(1970 \mathrm{a}, 1970 \mathrm{~b})$ index. Sentence frames were built around all of these nonwords, and there were four different sets of sentences, as shown in Appendix A, Table II. Sentences in the first set contained a nonword that sounded like an English homophone, and the sentence made sense when translated into a phonological code. The sentences in the second set were matched to these sentences for graphic similarity, but the nonword that sounded like an English word did not fit the phonological context of the sentence, so that the complete sentence did not make sense when translated into a phonological code. The third set of sentences contained the same nonwords that appeared in the second set of sentences, but all of the sentences made sense when translated into a phonological form. The fourth set of sentences were graphically similar to the third set, although the nonwords in them, which sounded like English homophones, did not fit the phonological context of the sentence, and the whole sentence was meaningless when translated into a phonological form. The graphic similarity between the nonwords and the English homophones and words they replaced in the sentences was calculated and is given alongside the subjects' errors in Appendix D.

The different sentence types were randomly assigned to four blocks, so that each block contained five sentences of each of the four types, to all of which the correct answer was "no." Each block also contained 20 filler items to which the correct answer was "yes." The same filler items were used in each block, but a different set of 20 test items was selected from the four sentence types and used in each block. Different children in each age group saw the different blocks.

Because of the difficulty of constructing the stimuli, only eight of the original nonwords from the first experiment could be used to derive the new nonwords. Two additional nonwords that sounded identical to English homophones were added, each of which had a corresponding homophone listed by Edwards and Gibbon (1973) as a word likely to be used by 6-year-olds, as were all the real words corresponding to the newly created nonwords.
Procedure. Testing took place at school during the morning. The children were tested in groups in their classrooms. Each session lasted approximately $30 \mathrm{~min}$. Within each grade, the children were randomly assigned to one of the four blocks of sentences. Questionnaires were distributed, and the children were asked to fill in personal details such as name, age, sex, and grade. The answering technique differed from Experiment 1 in that the children were asked to mark their responses to the questionnaires. Eight practice trials were presented to explain the nature of the task. The first four of these were already correctly filled in on the questionnaire to demonstrate to the children that a tick (check mark) meant that the sentence made sense, whereas a cross indicated that it did not. The next four practice examples were completed by the children and the experimenter together. When it was clear that the children understood the procedure, they were requested to turn to the second page of the questionnaire and to complete the remaining 40 items in the same way.

\section{Results}

Effects of graphic similarity. The percentage of correct "no" responses to the four types of sentence is shown in Table 6.

(1) Nonword (like English homophone): Sentence sounds correct vs. Nonword (like English word): Sentence sounds wrong. Performance was significantly worse for the former set of sentences than for the latter set, indicating that phonological encoding was taking place $[F(1,81=17.61, p<.001]$. Performance improved with age $[F(2,81)=9.79, p<.001]$, and there was a sex difference $[F(1,81)=6.54, p<.05]$. Six- and 7-year-old boys were more accurate than girls of those ages, whereas 8-year-old girls were marginally more accurate than 8-year-old boys, hence the Sex by Age interaction $[F(2,81)=3.24, p<.05]$. Ceiling effects may be present in the high level of performance of the 7. and 8-year-olds.

(2) Nonword (like English homophone): Sentence sounds wrong vs. Nonword (like English word): Sentence sounds correct. These two types of sentence were equated for graphic similarity. Performance was significantly worse on sentences in which the nonword sounded like a real word that would have been meaningful in the context $[F(1,81)=28.99, p<.001]$, again indicating phonological encoding. Performance improved with age $[F(2,81)=12.3, p<.001]$, and there was a Sentence by Age interaction, possibly due to ceiling effects, as all the children were accurate in rejecting the

Table 6

Percentage Correct "No" Responses Made by Children to Sentences in Experiment 4

\begin{tabular}{|c|c|c|c|}
\hline & \multicolumn{3}{|c|}{ Age in Years } \\
\hline & 6 & 7 & 8 \\
\hline $\begin{array}{l}\text { Phonologically meaningful sentences in which the nonword sounds like an English homophone } \\
\text { Phonologically meaningless sentences in which the nonword sounds like an English word }\end{array}$ & $\begin{array}{l}77.80 \\
89.63\end{array}$ & $\begin{array}{l}92.35 \\
98.24\end{array}$ & $\begin{array}{l}93.85 \\
96.92\end{array}$ \\
\hline $\begin{array}{l}\text { Phonologically meaningless sentences in which the nonword sounds like an English homophone } \\
\text { Phonologically meaningful sentences in which the nonword sounds like an English word }\end{array}$ & $\begin{array}{l}91.11 \\
69.63\end{array}$ & $\begin{array}{l}97.65 \\
86.47\end{array}$ & $\begin{array}{l}97.69 \\
95.38\end{array}$ \\
\hline
\end{tabular}

Note-The first two and the last two sentence types listed are graphically similar to each other. 
phonologically meaningless sentences, and the 7-yearolds did well on both sentence types $[F(2,81)=5.14$, $\mathrm{p}<.05$ ]

The correlations between graphic similarity and amount of errors calculated from the data in Appen. dix D, Table I were not significant. Therefore, although nonwords in the one set of sentences differed in graphic similarity from nonwords in the other set of sentences with respect to the correct word they replaced (e.g., "I noe on the door" vs. "I nok on the door"), this cannot be the explanation of the difference in error rates, since graphic similarity does not correlate with error rates; therefore, this difference, too, is evidence for phonological encoding.

\section{GENERAL DISCUSSION AND CONCLUSIONS}

The first experiment in this series suggested that, when children perform a task requiring silent reading of text for meaning, phonological recoding of the printed stimuli is employed to a considerable degree by young children. The older the child, the less evident phonological recoding is. Subsequent experiments provide reasons for rejecting claims that the effects observed in the first experiment were due to imperfect ability to spell homophones or to effects of visual similarity.

The extent to which phonological recoding is used by skilled adult readers has been a subject of debate throughout this century. Two major problems that have complicated the issue are (1) that many pronouncements for or against the phonological recoding hypothesis have not been accompanied by any evidence and (2) that when evidence is adduced, it is often of an inappropriate form. These problems have been discussed by Coltheart (1980). His conclusion was that, when one considers only evidence collected in methodologically appropriate ways, there is no clear evidence that adults reading single words for meaning use phonological recoding.

Few investigations of the role of phonological recoding in reading continuous text have been reported; very few of these have used appropriate techniques, and for this reason we know virtually nothing about phonological recoding during the reading of text. At least for single-word reading, however, it appears that phonological recoding is not a significant process for skilled reading.

Our suggestion is that when children begin to read, they rely to a great degree on phonological recoding. Over the next 4 or 5 years, the contributions of phonological recoding decrease, and reading for meaning relies more and more heavily on visual representations of words. There are several possibilities as to what might cause this shift. One is that it may be related to tuition in spelling, which is not usually extensive until a child has been reading for some time. A second possibility is that the words a child is given to read in early years are often deliberately selected; they are words with regular correspondences between grapheme and phoneme, that is, words that can correctly be recoded into phonological form by grapheme-phoneme correspondence rules. Only later are "irregular" or "exception" words introduced (Mathews, 1966); these cannot be recoded by standard grapheme-phoneme rules, and so require "visual" reading.

Learning to read by phonological recoding has its advantages and disadvantages. Among its advantages are that it allows reading to be parasitic upon speech comprehension (a process well developed in normal 5-yearolds), that what is learned generalizes to completely novel words, and that the method makes relatively modest demands upon rote learning capacities. Among its disadvantages are that learning of grapheme-phoneme correspondence is an abstract task and one whose relevance to understanding print may not be obvious to a 5-year-old; reading by phonological recoding cannot cope with exception words, nor with the task of distinguishing between homophones.

The traditional alternative method of learning to read, treating words as visual wholes, has no problems with exception words or homophones and allows immediate word comprehension, but it makes massive demands upon rote learning and does not permit generalization to visually novel words.

Since we have no a priori way of deciding which manner of learning to read has the superior balance of advantages over disadvantages, what is needed is evidence concerning which of the advantages are important and which of the disadvantages severe. Very much more evidence of this kind is needed than is yet available, but some relevant points can be made. For example, Japanese is written in a mixture of two scripts, Kanji (similar to the Chinese script; it is ideographic, so it can only be learned on a whole-word basis) and Kana (a syllabic script ideally designed for learning by phonological recoding). The practice in Japan is for children to learn to read Kana first (most children have mastered it before even coming to school) and then gradually, over a period of several years, to learn to read Kanji. In this sense, 6-year-old Japanese children rely almost exclusively on phonological recoding, whereas 10-year-old Japanese children make substantial use of visual recoding. Our results suggest that this is true of English children, too.

\section{REFERENCE NOTE}

1. Calfee, R. C., Venezky, R. L., \& Chapman, R. S. Pronunciation of synthetic words with predictable and unpredictable lettersound correspondences (Tech. Rep. 71). Wisconsin Research and Development Center for Cognitive Learning, 1969.

\section{REFERENCES}

Baron, J. Phonemic stage not necessary for reading. Quarterly Journal of Experimental Psychology, 1973, 25, 241-246.

Chall, J. Learning to read: The great debate. New York: McGraw-Hill, 1967. 
Clank, H. H. The language-as-fixed-effect fallacy: A critique of language statistics in psychological research. Journal of Verbal Learning and Verbal Behavior, 1973, 12, 335-359.

Coltheart, M. Lexical access in simple reading tasks. In G. Underwood (Ed.), Strategies in information processing. London: Academic Press, 1978.

Coltheart, M. Reading, phonological encoding and deep dyslexia. In M. Coltheart, K. Patterson, \& J. C. Marshall (Eds.), Deep dyslexia. London: Routledge \& Kegan Paul, 1980.

Downing, J., \& Thackray, D. Reading readiness, London: University of London Press, 1971.

Edwards, R. P. A., \& Gibion, V. Words your children use. London: Burke Books, 1964.

FIRTH, I. Components of reading disability. Unpublished doctoral dissertation, University of New South Wales, 1972.

Forster, K. I., \& Chambers, S. H. Lexical access and naming time. Journal of Verbal Learning and Verbal Behavior, 1973, $12,627-635$

KuCERA, H., \& Francis, W. N. Computational analysis of present-day American English. Providence, R.I: Brown University Press, 1970.

Marshall, J. C., \& Newcombe, F. Patterns of paralexia. Journal of Psycholinguistic Research, 1973, 2, 175-199.

Mathews, M. M. Teaching to read. Chicago: University of Chicago Press, 1966.

NeALE, M. Neale analysis of readability. Houndsmills, Basingstoke, Hants., England: Macmillan Educational, 1967.

Rozin, P., Bressman, B., \& TAFT, M. Do children understand the basic relationship between speech and writing? The mowmotorcycle test. Journal of Reading Behaviour, 1974, 6, 327-334.

Schonell, F. Schonell graded word reading test. Edinburgh: Oliver \& Boyd, 1945.
Sebesta, S. L. Artificial orthography as a transitional device in first grade reading instruction. Journal of Educational Psychology, 1964, 55, 253-257.

Shallice, T., \& Warrington, E. K. Word recognition in a phonemic dyslexic patient. Quarterly Journal of Experimental Psychology, 1975, 27, 187.199.

Thackray, D. V. Reading for meaning with i.t.a. and t.o. London: Geoffrey Chapman, 1971.

Thompson, G. B. Sex differences in reading attainments. Educa tional Research, 1975, 18, 16-23.

WEBER, R. M. First-graders' use of grammatical context in reading. In $\mathrm{H}$. Levin \& J. P. Williams (Eds.), Basic studies on reading. New York: Basic Books, 1970. (a)

Weber, R. M. A linguistic analysis of first-grade reading errors. Reading Research Quarterly, 1970, 5, 427-451. (b)

Wike, E. L., \& Church, J. D. Comments on Clark's "The language-as-fixed-effect fallacy." Journal of Verbal Learning and Verbal Behavior, 1976, 15, 249-255.

\section{NOTES}

1. Initial teaching alphabet (i.t.a.) is a simplification of English orthography in which the mapping of letters onto phonemes is highly regular (see, e.g., Thackray, 1971, Chapter 3). It was used quite widely for teaching reading in England in the 1960s.

2. Further analyses of these data were carried out using the min F' method advocated by Clark (1973), which treats both subjects and sentences as random effects. It is controversial whether this is necessary, or even justifiable (Wike \& Church, $1976)$. Fortunately, we have no need to take sides in this controversy, since all of the effects that are significant in the analyses we report remain significant when $\min \mathbf{F}^{\prime}$ is used.

\section{APPENDIX A}

Table I

List of 144 Sentences Used in Experiment 1

WOOD

We walk in the street

We walk in the wood

We walk in the would

We walk in the woud

We walk in the wun

We walk in the won

So

This house is very big

This house is so big

This house is sew big

This house is soe big

This house is throo big

This house is threw big

SEA

We swim in the water

We swim in the sea

We swim in the see

We swim in the cea

We swim in the faw

We swim in the four

BY

He went into the town

He went by the town

He went buy the town

He went bie the town

He went thair the town

He went their the town

\section{WOULD}

Jane will come with us Jane would come with us Jane wood come with us Jane woud come with us Jane wun come with us

Jane one come with us SEW

She will make a dress

She will sew a dress

She will so a dress

She will soe a dress

She will throo a dress

She will through a dress

SEE

I will call him today

I will see him today

I will sea him today

I will cea him today

I will faw him today

I will for him today

BUY

She will give him a toy

She will buy him a toy

She will by him a toy

She will bie him a toy

She will thair him a toy

She will there him a toy
BLUE

The sky is big

The sky is blue

The sky is blew

The sky is bloo

The sky is noe

The sky is no

NEW

Tell us a funny story

Tell us a new story

Tell us a knew story

Tell us a nue story

Tell us a wair story

Tell us a where story

WON

That boy has a toy

That boy won a toy

That boy one a toy

That boy wun a toy

That boy woud a toy

That boy wood a toy

THREW

He hit the ball

He threw the ball

He through the ball

He throo the ball

He soe the ball

He so the ball
BLEW

She picks up the balloon

She blew up the balloon

She blue up the balloon

She bloo up the balloon

She noe up the balloon

She know up the balloon

KNEW

I saw that boy

I knew that boy

I new that boy

I nue that boy

I wair that boy

I wear that boy

ONE

All of us will come

One of us will come

Won of us will come

Wun of us will come

Woud of us will come

Would of us will come

\section{THROUGH}

He ran in the street

He ran through the street

He ran threw the street

He ran throo the street

He ran soe the street

He ran sew the street 
Table I Continued

FOUR

I have five dogs

I have four dogs

I have for dogs

I have faw dogs

I have cea dogs

I have sea dogs

THEIR

We will stay at my house

We will stay at their house

We will stay at there house

We will stay at thair house

We will stay at bie house

We will stay at by house
FOR

The toy is with John

The toy is for John

The toy is four John

The toy is faw John

The toy is cea John

The toy is see John

THERE

That is a leaf on the tree

There is a leaf on the tree

Their is a leaf on the tree

Thair is a leaf on the tree

Bie is a leaf on the tree

Buy is a leaf on the tree
NO

I have the time

I have no time

I have know time

I have noe time

I have bloo time

I have blue time

WHERE

Tell me why he went

Tell me where he went

Tell me wear he went

Tell me wair he went

Tell me nue he went

Tell me new he went
KNOW

I like your name

I know your name

I no your name

I noe your name

I bloo your name

I blew your name

WEAR

I will have a green dress

I will wear a green dress

I will where a green dress

I will wair a green dress

I will nue a green dress

$I$ will knew a green dress

Table II

List of 80 Sentences Used in Experiment 4

(BUY, BIE, and BEL are (BY, BIE, and BAK are (WHERE, WAIR, and WOAR graphically similar)

She will bie him a toy

I ring the bie

I ring the bel

She will bel him a toy

(SEA, CEA, and BEA are graphically similar)

We swim in the cea

A cea can fly

A bea can fly

We swim in the bea

(NEW, NUE, and NOE are graphically similar)

Tell us a nue story

She said nue to him

She said noe to him

Tell us a noe story

(ONE, WUN, and KAN are graphically similar)

Wun of us will come

I wun sing a song

I kan sing a song

Kan of us will come

(FOUR, FAW, and FEL are graphically similar)

I have faw dogs

I faw down

I fel down

I have fel dogs graphically similar)

He went bie the town

Let's go bie to the house

Let's go bak to the house

He went bak the town

(SEE, CEA, and KEA are graphically similar)

I will cea him today

I have a cea for the door

I have a kea for the door

I will kea him today

(KNEW, NUE, and WUN are graphically similar)

I nue what to tell him

$\mathrm{He}$ is nue of my friends

$\mathrm{He}$ is wun of my friends

I wun what to tell him

(WON, WUN, and WEN are graphically similar)

That boy wun a toy

Wun are you going home?

Wen are you going home?

That boy wen a toy

(FOR, FAW, and FIL are graphically similar)

The toy is faw John

He will faw the box with sand

$\mathrm{He}$ will fil the box with sand The toy is fil John are graphically similar)

Tell me wair he went

They fight in the wair

They fight in the woar

Tell me woar he went

(NO, NOE, and NOK are graphically similar)

I have noe time

I noe on the door

I nok on the door

I have nok time

(ATE, AIT, and ATT are

graphically similar)

Tom ait his apple

My dog is ait home

My dog is att home

Tom att his apple

(BE, BEA, and BEL are graphically similar)

He wants to bea a doctor

The bea is ringing

The bel is ringing

He wants to bel a doctor

(BLUE, BLOO, and BLAK are graphically similar)

The sun shines in the bloo sky

That man is bloo

That man is blak

The sun shines in the blak sky
(WEAR, WAIR, and WAUR

are graphically similar)

I will wair a green dress

He fights in the wair

He fights in the waur

I will waur a green dress

(KNOW, NOE, and NOK are graphically similar)

I noe him

Noe is white

Sno is white

I sno him

(EIGHT, AIT, and ITT are graphically similar)

He is ait years old

Ait is hot today

Itt is hot today

He is itt years old

(BEE, BEA, and BEL are graphically similar)

A bea can fly

She rings the bea

She rings the bel

A bel can fly

(BLEW, BLOO, and BLAK

are graphically similar)

She bloo up the balloon

That girl is bloo

That girl is blak

She blak up the balloon

\section{APPENDIX B}

Table I

Percentage of Substitutions (PS), Graphic Similarity (GS), Word Frequency (WF), and Errors for Homophones

\begin{tabular}{lcccrr}
\hline Presented as & Used as Meaning & PS & GS & WF & Errors \\
\hline NO & KNOW & 7.5 & 258.33 & 2201 & 2 \\
KNOW & NO & 2.5 & 258.33 & 683 & 5
\end{tabular}


Table I Continued

\begin{tabular}{|c|c|c|c|c|c|}
\hline Presented as & Used as Meaning & PS & GS & WF & Errors \\
\hline ONE & WON & .0 & 283.33 & 3292 & 5 \\
\hline WON & ONE & 5.0 & 283.33 & 68 & 2 \\
\hline SEW & SO & 7.5 & 343.50 & 6 & 2 \\
\hline so & SEW & .0 & 343.50 & 1984 & 2 \\
\hline WHERE & WEAR & 7.5 & 376.67 & 938 & 8 \\
\hline WEAR & WHERE & 10.0 & 376.67 & 36 & 3 \\
\hline BLEW & BLUE & 7.5 & 520.00 & 12 & 3 \\
\hline BLUE & BLEW & .0 & 520.00 & 143 & 3 \\
\hline THROUGH & THREW & 30.0 & 522.17 & 969 & 7 \\
\hline THREW & THROUGH & 12.5 & 522.17 & 46 & 3 \\
\hline SEE & SEA & .0 & 553.33 & 772 & 1 \\
\hline SEA & SEE & .0 & 553.33 & 95 & 2 \\
\hline BY & BUY & 12.5 & 563.50 & 5305 & 8 \\
\hline BUY & BY & 10.0 & 563.50 & 70 & 3 \\
\hline NEW & KNEW & 5.0 & 588.93 & 1635 & 8 \\
\hline KNEW & NEW & 25.0 & 588.93 & 395 & 3 \\
\hline THERE & THEIR & .0 & 600.00 & 2724 & 8 \\
\hline THEIR & THERE & 42.5 & 600.00 & 2670 & 3 \\
\hline WOULD & WOOD & 7.5 & 607.78 & 2714 & 0 \\
\hline WOOD & WOULD & 7.5 & 607.78 & 55 & 3 \\
\hline FOR & FOUR & 2.5 & 716.07 & 9489 & 3 \\
\hline FOUR & FOR & 7.5 & 716.07 & 359 & 1 \\
\hline
\end{tabular}

Note-Word frequencies given are those for the presented homophones.

Table II

Percentage Substitutions (PS), Graphic Similarity (GC) Scores, Word Frequency (WF) Scores, and Errors for Nonwords

\begin{tabular}{|c|c|c|c|c|c|}
\hline Presented as & Used as Meaning & PS & GS & WF & Errors \\
\hline WUN & ONE & 5.0 & 83.30 & 3292 & 1 \\
\hline CEA & SEE & 15.0 & 83.30 & 772 & 1 \\
\hline NUE & KNEW & 12.5 & 94.60 & 395 & 1 \\
\hline NOE & KNOW & 12.5 & 237.50 & 683 & 1 \\
\hline FAW & FOUR & 2.5 & 336.07 & 359 & 2 \\
\hline $\mathrm{BIE}$ & BY & 5.0 & 343.50 & 5305 & 0 \\
\hline BIE & BUY & 30.0 & 353.33 & 70 & 1 \\
\hline FAW & FOR & 10.0 & 353.33 & 9489 & 2 \\
\hline WAIR & WHERE & 17.5 & 354.44 & 938 & 4 \\
\hline SOE & SEW & 22.5 & 386.67 & 6 & 2 \\
\hline NUE & NEW & 20.0 & 386.67 & 1635 & 2 \\
\hline CEA & SEA & 10.0 & 463.30 & 95 & 3 \\
\hline THAIR & THERE & 40.0 & 480.00 & 2724 & 4 \\
\hline BLOO & BLUE & 5.0 & 495.00 & 143 & 6 \\
\hline BLOO & BLEW & 32.5 & 495.00 & 12 & 4 \\
\hline WUN & WON & 4.75 & 566.67 & 68 & 5 \\
\hline WAIR & WEAR & 32.5 & 575.00 & 36 & 4 \\
\hline THROO & THREW & 22.5 & 580.00 & 46 & 3 \\
\hline NOE & NO & 12.5 & 583.50 & 2201 & 1 \\
\hline THROO & THROUGH & 27.5 & 583.50 & 969 & 2 \\
\hline WOUD & WOOD & 7.5 & 700.00 & 55 & 1 \\
\hline THAIR & THEIR & 7.5 & 780.00 & 2670 & 5 \\
\hline SOE & SO & 7.5 & 783.50 & 1984 & 2 \\
\hline WOUD & WOULD & 35.0 & 801.11 & 2714 & 6 \\
\hline
\end{tabular}


APPENDIX C

Table I

Percentage Correct "No" Responses (PC) to All-Word Sentences Containing Meaningless but Phonologically Appropriate

Homophones and Percentage Incorrect Usage of Homophones by Substitution (PI) Given for Children Aged 6-10 Years

\begin{tabular}{llrr}
\hline Presented as & Used as Meaning & PC & \multicolumn{1}{c}{ PI } \\
\hline NO & KNOW & 80 & 7.5 \\
KNOW & NO & 50 & 2.5 \\
ONE & WON & 50 & .0 \\
WON & ONE & 80 & 5.0 \\
SEW & SO & 80 & 7.5 \\
SO & SEW & 80 & .0 \\
WHERE & WEAR & 20 & 7.5 \\
WEAR & WHERE & 70 & 10.0 \\
BLEW & BLUE & 70 & 7.5 \\
BLUE & BLEW & 70 & .0 \\
THROUGH & THREW & 30 & 30.0 \\
THREW & THROUGH & 70 & 12.5 \\
SEE & SEA & 90 & .0 \\
SEA & SEE & 80 & .0 \\
BY & BUY & 20 & 12.5 \\
BUY & BY & 70 & 10.0 \\
NEW & KNEW & 20 & 5.0 \\
KNEW & NEW & 70 & 25.0 \\
THERE & THEIR & 20 & .0 \\
THEIR & THERE & 70 & 42.5 \\
WOULD & WOOD & 100 & 7.5 \\
WOOD & WOULD & 70 & 7.5 \\
FOR & FOUR & 70 & 2.5 \\
FOUR & FOR & 90 & 7.5 \\
\hline & & &
\end{tabular}

Table 11

Percentage Correct "No" Responses (PC) to Meaningless Sentences in Which the Nonword Sounded Correct and Percentage Incorrect Usage of Nonwords as Homophones (PI) by Children Aged 6-10 Years

\begin{tabular}{llrr}
\hline Presented as & Used as Meaning & PC & PI \\
\hline WUN & ONE & 90 & 5.0 \\
CEA & SEE & 90 & 15.0 \\
NUE & KNEW & 90 & 12.5 \\
NOE & KNOW & 90 & 12.5 \\
FAW & FOUR & 80 & 2.5 \\
BIE & BY & 100 & 5.0 \\
BIE & BUY & 90 & 30.0 \\
FAW & FOUR & 80 & 10.0 \\
WAIR & WHERE & 60 & 17.5 \\
SOE & SEW & 80 & 22.5 \\
NUE & NEW & 80 & 20.0 \\
CEA & SEA & 70 & 10.0 \\
THAIR & THERE & 60 & 40.0 \\
BLOO & BLUE & 40 & 5.0 \\
BLOO & BLEW & 60 & 32.5 \\
WUN & WON & 50 & 4.75 \\
WAIR & WEAR & 60 & 32.5 \\
THROO & THREW & 70 & 22.5 \\
NOE & NO & 90 & 12.5 \\
THROO & THROUGH & 80 & 27.5 \\
WOUD & WOOD & 90 & 7.5 \\
THAIR & THEIR & 50 & 7.5 \\
SOE & SO & 80 & 7.5 \\
WOUD & WOULD & 40 & 35.0 \\
\hline
\end{tabular}

\section{APPENDIX D}

Table I

Graphic Similarity (GS) Scores for the Different Types of Items and Corresponding Errors for Experiment 4

\begin{tabular}{|c|c|c|c|c|c|c|c|c|c|c|c|c|}
\hline \multicolumn{2}{|c|}{ Presented as } & \multirow{2}{*}{$\begin{array}{c}\text { Meaning } \\
\text { (3) }\end{array}$} & \multirow{2}{*}{$\begin{array}{l}\text { GS } \\
(4) \\
\end{array}$} & \multicolumn{2}{|c|}{ Errors } & \multicolumn{2}{|c|}{ Presented as } & \multirow{2}{*}{$\begin{array}{c}\text { Meaning } \\
(9)\end{array}$} & \multicolumn{2}{|c|}{ GS } & \multicolumn{2}{|c|}{ Errors } \\
\hline (1) & (2) & & & $(5)$ & (6) & (7) & (8) & & $(10)$ & (11) & (12) & (13) \\
\hline WUN & KAN & ONE & 83.30 & 2 & 0 & KAN & WUN & CAN & 463.33 & 263.30 & 3 & 2 \\
\hline CEA & KEA & SEE & 83.30 & 1 & 1 & KEA & CEA & KEY & 533.33 & 83.30 & 5 & 1 \\
\hline NUE & WUN & KNEW & 94.64 & 2 & 0 & WUN & NUE & ONE & 83.30 & 296.70 & 2 & 1 \\
\hline NOE & SNO & KNOW & 237.50 & 2 & 0 & SNO & NOE & SNOW & 746.79 & 237.50 & 0 & 0 \\
\hline FAW & FEL & FOUR & 336.07 & 0 & 2 & FEL & FAW & FELL & 858.93 & 336.10 & 7 & 1 \\
\hline BIE & BAK & BY & 343.50 & 1 & 0 & BAK & BIE & BACK & 716.07 & 336.10 & 4 & 0 \\
\hline BIE & BEL & BUY & 353.33 & 2 & 0 & BEL & BIE & BELL & 858.93 & 354.60 & 4 & 4 \\
\hline FAW & FIL & FOR & 353.33 & 2 & 0 & FIL & FAW & FILL & 858.93 & 336.10 & 5 & 0 \\
\hline WAIR & WOAR & WHERE & 354.44 & 6 & 2 & WOAR & WAIR & WAR & 716.07 & 716.07 & 2 & 1 \\
\hline NUE & NOE & NEW & 386.67 & 4 & 0 & NOE & NUE & NO & 583.50 & 343.50 & 0 & 0 \\
\hline CEA & BEA & SEA & 463.30 & 2 & 0 & BEA & CEA & BEE & 553.33 & 83.30 & 7 & 0 \\
\hline BLOO & BLAK & BLUE & 495.00 & 1 & 2 & BLAK & BLOO & BLACK & 801.10 & 465.60 & 6 & 0 \\
\hline BLOO & BLAK & BLEW & 495.00 & 5 & 1 & BLAK & BLOO & BLACK & 801.10 & 465.60 & 3 & 2 \\
\hline WUN & WEN & WON & 566.67 & 2 & 2 & WEN & WUN & WHEN & 716.07 & 554.60 & 3 & 2 \\
\hline WAIR & WAUR & WEAR & 575.00 & 8 & 0 & WAUR & WAIR & WAR & 716.07 & 716.07 & 3 & 2 \\
\hline NOE & NOK & No & 583.50 & 3 & 0 & NOK & NOE & KNOCK & 410.00 & 205.00 & 4 & 2 \\
\hline AIT & ITT & EIGHT & 260.00 & 0 & 1 & ITT & AIT & IT & 763.50 & 493.50 & 1 & 1 \\
\hline AIT & ATT & ATE & 386.70 & 2 & 3 & ATT & AIT & AT & 763.50 & 563.50 & 2 & 1 \\
\hline BEA & BEL & BEE & 553.30 & 3 & 1 & BEL & BEA & BELL & 858.93 & 507.50 & 4 & 1 \\
\hline BEA & BEL & $\mathrm{BE}$ & 583.50 & 3 & 2 & BEL & BEA & BELL & 858.93 & 507.50 & 6 & 0 \\
\hline
\end{tabular}

Note-Column 4 refers to the GS scores of the corresponding words and nonwords in Columns 1, 2, and 3. All three have the same $G S$ score except for the entries on Line 18: ATE and ATT have a greater GS of 513.30. Column 5 refers to errors made by accepting nonwords in Column 1 as meaning the same as homophones in Column 3. Column 6 refers to errors made by accepting nonwords 
in Column 2 as meaning the same as the homophones in Column 3, from which they differ phonologically even though they are graphically similar. Column 10 refers to the GS between the nonword in Column 7 and the corresponding word in Column 9. Column 11 refers to the GS between the nonword in Column 8 and the corresponding word in Column 9 . Column 12 refers to errors made in accepting the nonword in Column 7 as meaning the same as the phonologically similar word in Column 9. Column 13 refers to errors made in accepting the nonword in Column 8 as meaning the same as the word in Column 9 although the two are phonologically different.

(Received for publication September 25, 1979; revision accepted December 22, 1979.) 